\title{
Getting to work: smart work centers reduce morning peak traffic flow
}

\author{
$\underline{\text { Timothy M. Baynes }}^{\mathrm{a}}$, Tao Wen ${ }^{\mathrm{b}}$, Hoang Nguyen ${ }^{\mathrm{b}}$ and Fang Chen $^{\mathrm{b}}$ \\ ${ }^{a}$ CSIRO Land and Water, North Ryde, NSW \\ ${ }^{b}$ CSIRO Data61, Eveleigh, NSW \\ Email: tim.baynes@,csiro.au
}

\begin{abstract}
Current transport planning in Australia appears to concentrate on increasing supply of transport infrastructure and services and we invert the problem and consider a transport demand management option: smart work centers or hubs located 'close to load'. Smart work centres are an alternative to CBD office space or home-based work or "third space" options like libraries and cafes. Well-equipped, connected and secure, they are small scale and designed to accommodate small businesses, collaborations and corporate employees working closer to where they live. In principle this is the workplace analogue of water saving devices in the home or distributed energy generation. However, the implementation of smart work centers (SWC) is sparse or close to existing major workplace locations. The research question of this paper is: if SWCs were specifically located near where commuting populations reside (rather than where they work) how would multiple SWCs influence traffic flow on a key arterial road in Sydney?
\end{abstract}

We selected Sydney CBD as a destination zone from the NSW Bureau of Transport Statistics' origindestination peak AM data on trips and travel time. We selected only trips by non-mass transit passenger vehicles and used census data to further selected for occupation types that would use a SWC (exclusively Managers, Professionals, Clerical and administrative workers). From this we ranked the origin zones that had the greatest potential for a SWC based on peak AM person hours commuting.

For this proof of principle exercise, we selected two segments of Parramatta Road (Sydney's main western arterial road), which have AM peak flows of $\sim 1600$ vehicles/hour. From the Sydney Coordinated Adaptive Traffic System (SCATS) we obtained vehicle flow rate and speed data for 15 minute intervals over the AM peak for the study segments. From this we derived an elasticity of travel time with flow rate with a parabolic regression function.

Based on detailed census and traffic flow data, and a conservative assumption about SWC utilization (50\%), we find that 8 SWCs can reduce flow by more than 80 vehicles/hour. This equates to all commuters saving approximately 1minute travel time on the study road segments. This is a promising result that suggests further research is worthwhile: investigating the effect of a larger population of SWC on the same study segment; assessing the effect of a larger population of SWC on the metropolitan road network and; surveying the commuting population regarding likely uptake.

Keywords: $\quad$ Origin, destination, transport modeling, work hub, congestion, commuting 
Baynes, Wen, Nguyen and Chen, Getting to work: smart work centers reduce morning peak traffic flow

\section{INTRODUCTION}

Major Australian cities are projected to see increasing populations (ABS 2013) over the next 50 years and, with that, increases in aggregate urban traffic is likely over at least the next 15 years: total vehicle-kilometers travelled (VKT) are forecast to increase around 2 per cent per annum out to 2030 (BITRE 2015).

Transport infrastructure projects of the recent past, and ongoing major transport infrastructure projects, have focused on augmenting capacity (Veitch Lister Consulting Pty Ltd 2014). Although a recent report by Infrastructure Australia (2016) also emphasizes capacity building, it recognizes that "current expenditure levels are unlikely to be sufficient to provide the infrastructure Australia needs over coming decades" (p23). Among several recommendations in that same report are: better use of existing infrastructure, better connectivity and access to employment opportunities in outer suburbs, and better governance coordination and long-term planning for metropolitan infrastructure.

Within this context we investigate a novel approach to urban employment and commuting: demand management in private transport. Specifically, we look at the effects on travel time in Sydney's peak AM commuting with the implementation of multiple smart work centres (SWC). Smart work centres are an alternative to CBD office space or home-based work or "third space" options like libraries and cafes. Wellequipped, connected and secure, they are small scale and designed to accommodate small businesses, collaborations and corporate employees working closer to where they live. In principle this is the workplace analogue of water saving devices in the home or distributed energy generation 'close to load'. The supply of a service is made more efficient by being close to demand. Here, a workplace is proximal to the (end-user) employee, not the employer.

Multiple SWC have been set up in Amsterdam, Silicon Valley and in Singapore and Korea and the NSW State Government has supported 5 SWCs in Western Sydney and the NSW Central Coast ${ }^{1}$, which we distinguish from work hubs near existing employment destinations that are intended to be creative spaces engendering collaboration and innovation.

Shared services at SWCs increase operational efficiency and reduce costs. Buksch and Davidson (2014) found that "if [SWC] (excluding Brisbane CBD) accommodated 10\% more highly skilled jobs growth, an extra \$3 billion one-off benefit would be generated, plus ongoing benefit of $\sim \$ 1.6$ billion pa." Wilmot et al (2014) simulated the implementation of only 3 SWC in the Sydney area and calculated they could collectively save 12,000 tons of greenhouse gas emissions in addition to saving $\$ 56$ million (or nearly $\$ 8000$ per worker) in public and private costs per year. These prior studies have looked at scenarios of SWC locations and their general benefit to a metro area and/or to the SWC users.

The innovation of the present research is an empirically-based choice of SWC location where commuting populations reside (rather than where they work) and a bottom-up simulation of multiple SWCs with a transport model to enumerate their influence on traffic flow and peak AM travel-time for a key arterial road in Sydney.

The overarching hypothesis is that SWC can produce economic, environmental and social benefits through reduced demand on transport infrastructure, reduced commuting time and reduced transport emissions at the metropolitan scale. We believe that a metropolitan system of SWC would have a greater effect than the sum of individual centres; that there would be a further productivity and environmental dividend from network effects.

\section{DATA AND METHODS}

Our approach begins with empirical observations to determine potential locations for SWC at the level of the suburb, which we define by SA2 boundaries from the Australian Standard Geographical Classification (see Figure 1). By definition SA2 boundaries “...represent a community that interacts together socially and economically... generally have a population range of 3,000 to 25,000 persons, with an average population of about 10,000 persons" (ABS 2011a). Raw data from the 2011 Australian Census (ABS 2011b) on occupations by SA2 boundaries for the Sydney Greater Metropolitan Area (GMA) were used to identify locations where "white collar" service workers reside. Subsequent to this, there were 6 basic tasks:

1. Derive an origin destination matrix from journeys to work (JTW) data for only those occupations that would use a SWC (as identified from the census data).

\footnotetext{
${ }_{1 \text { https://www.industry.nsw.gov.au/business-and-industry-in-nsw/assistance-and-support/smart-work-hubs }}$
} 
Baynes, Wen, Nguyen and Chen, Getting to work: smart work centers reduce morning peak traffic flow

2. Identify a test SA2 destination and further filter JTW data for motorised private transport for one or more routes by which commuters arrive at that destination (This was chosen to be Sydney CBD due to the job density in that SA2).

3. Select a set of candidate origin SA2s for SWCs based on the combination of the commuting time to the test destination, and numbers of persons at origin SA2 area working in the relevant occupations.

4. From the selection in Step 3., identify only trips that would make use of a selection of road segments of a major road for specific analysis.

5. Obtain the flow velocity regression curve for the usual peak AM conditions on those segments based on detail traffic data, and...

6. Finally, estimating what effect a reduction in flow due to SWC utilization would do for velocity and hence travel time.

For Steps 1 and 2, we used the JTW data in Tables 5 and 17 from the NSW Bureau of Transport Statistics (BTS 2011b) mapping their geography of travel zones (TZ) to SA2 using the concordances provided by BTS. Census data provided a measure of the number of potential commuters at their SA2 origins: where "white collar' workers could come from - selecting only these census data occupation categories that are amenable to remote working:

- 'Managers 2011 Census Persons'

- 'Professionals 2011 Census Persons'

- 'Clerical and administrative workers 2011 Census Persons'

Table 5 of the JTW data provided information on the work destinations of those occupations, and Table 17 provided data on the flows between specific origin-destination pairs by transport mode (mode was filtered for non-truck, motorized modes of private transport).

This preparation of the data allows for an analysis of potential SWC users by many origins and destinations but for our proof-of-principal purposes here, we selected Sydney CBD (SA2 117031337) as the sole test case destination due to the large number of work destinations there $(183,000$ white collar commuters from outside Sydney CBD). Sydney CBD might also be justified from the perspective of large institutional employers, as they are exactly the tenants of commercial buildings with high CBD rents, employing thousands of people who commute to this centralized location. From a large institutional employer perspective, it might be expected that there would be an interest in alternative accommodation for CBD workers.

For Step 3, further data on average time spent in vehicles (minutes) for the AM peak was obtained from BTS's skim matrices database (BTS 2011a). Data were available by TZ for Sydney GMA and were again concorded to SA2 boundaries. SA2 areas with an average peak AM commuting time to Sydney CBD $>=50$ minutes were selected as candidate locations for SWC (see Table 1). Steps $4-6$ are embedded in input assumptions and the transport model.

\subsection{Assumptions of the model}

The commuters' route choice between origin and destination is essential to determine the traffic flow reduction of particular road segments. Data from BTS provides ample information on origins, destinations, mode and time in-vehicle but it does not specify routes. We assumed that commuters choose major arterial roads rather than tertiary roads. The selected route for West to East commuting to Sydney CBD is shown in red in Figure 1. The proportion of all commuters travelling in this direction, taking this route, is assumed to be 0.8 . If more detail were available, more advanced but complicated transportation route choice models could be utilized, such as the logit assignment model (Bell and Iida 1997).

The capacity of individual SWC was assumed to be 60 persons (based on the approximate size of existing $\mathrm{SWC}^{1}$ ). Utilization of SWC was assumed modified by two factors: a $30 \%$ uptake by local commuters (in the relevant occupations) and, on any given morning, up to 50\% of SWC capacity would be in use. Thus we have estimates for 'Potential SWC users' based only on uptake and 'Simulated SWC users' used in calculations subsequent to the utilization condition (refer to Table 1). Actual utilization is commercially sensitive information and we have been deliberately conservative on uptake in the absence of data. Our assumption may be compared with some teleworking statistics in Europe (INRE 2013). The choice of 50\% does not commit the modeling to over or under utilization. Further research on uptake factors such as population agestructure at origin could be important in evaluating uptake and utilization rate of SWC. For example, areas with young families may be more inclined to use work options close-to-home if they were available. 


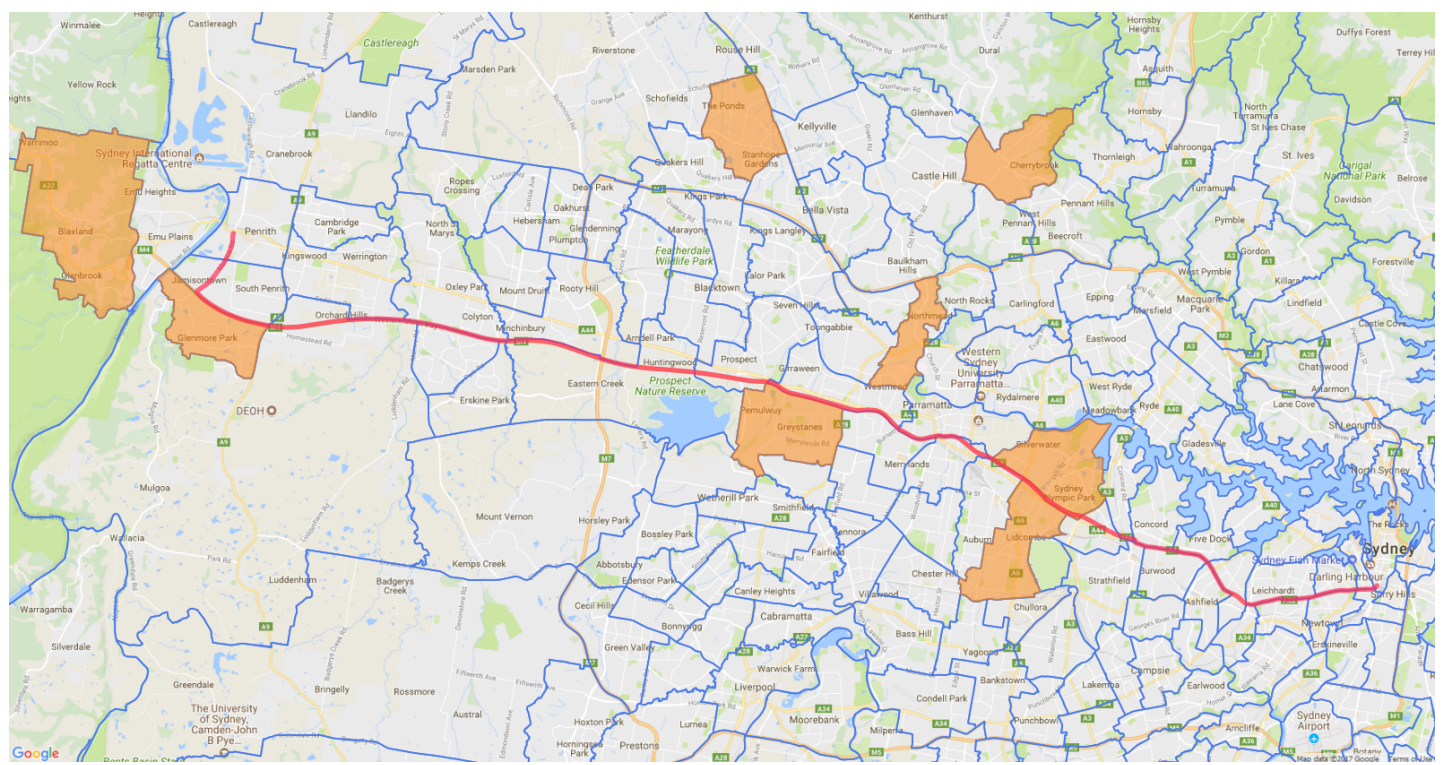

Figure 1. Section of Sydney GMA study area showing assumed route taken, SA2 boundaries and specific SA2 locations that were candidates for smart work centres (listed in Table 1).

Table 1. Top 8 candidate SA2 origin locations for SWC, ranked on peak AM commuting time $>=50$ minutes. Total potential time saving (Person.time) is the product of total trips and average time in vehicle. Note that some totals and calculations presented may not match due to rounding of actual data. ${ }^{\wedge}$ for relevant occupations, * peak AM commuting is considered to have a 2.5 hour interval between 6:30am and 9:00am

\begin{tabular}{|l|c|c|c|c|c|c|}
\hline $\begin{array}{c}\text { Candidate SA2 } \\
\text { locations for } \\
\text { SWC }\end{array}$ & $\begin{array}{c}\text { Trips } \\
\text { to } \\
\text { Sydney } \\
\text { CBD }^{\wedge}\end{array}$ & $\begin{array}{c}\text { Average } \\
\text { Time in } \\
\text { vehicle } \\
\text { (mins) }\end{array}$ & $\begin{array}{c}\text { Person } \\
\text { time } \\
\text { (mins) }\end{array}$ & $\begin{array}{c}\text { Potential } \\
\text { SWC } \\
\text { users }\end{array}$ & $\begin{array}{c}\text { Simulated } \\
\text { SWC } \\
\text { users }\end{array}$ & $\begin{array}{c}\text { Potential } \\
\text { flow rate } \\
\text { roduction } \\
\text { (veh/hr)* }\end{array}$ \\
\hline $\begin{array}{l}\text { Blaxland - } \\
\text { Warrimoo - } \\
\text { Lapstone }\end{array}$ & 62 & 123 & 7631 & 19 & 19 & 7 \\
\hline $\begin{array}{l}\text { Glenmore Park - } \\
\text { Regentville }\end{array}$ & 48 & 115 & 5510 & 14 & 14 & 6 \\
\hline $\begin{array}{l}\text { Parklea - } \\
\text { Kellyville Ridge }\end{array}$ & 116 & 82 & 9539 & 35 & 30 & 12 \\
\hline $\begin{array}{l}\text { Greystanes - } \\
\text { Pemulwuy }\end{array}$ & 82 & 77 & 6371 & 25 & 25 & 10 \\
\hline Northmead & 88 & 68 & 6035 & 26 & 26 & 11 \\
\hline Cherrybrook & 234 & 64 & 14943 & 70 & 30 & 12 \\
\hline $\begin{array}{l}\text { Lidcombe - } \\
\text { Regents Park }\end{array}$ & 108 & 56 & 6060 & 32 & 30 & 12 \\
\hline $\begin{array}{l}\text { Homebush Bay - } \\
\text { Silverwater }\end{array}$ & 152 & 55 & 8325 & 46 & 30 & 12 \\
\hline Total & $\mathbf{8 9 0}$ & & $\mathbf{6 4 4 1 4}$ & $\mathbf{2 6 7}$ & $\mathbf{2 0 6}$ & $\mathbf{8 2}$ \\
\hline
\end{tabular}


Baynes, Wen, Nguyen and Chen, Getting to work: smart work centers reduce morning peak traffic flow

\subsection{The transport model}

The fundamental diagram of traffic flow is a relation between the traffic flow (vehicles/hour) and the traffic density (vehicles $/ \mathrm{km}$ ). A macroscopic traffic model involving traffic flow, traffic density and velocity forms the basis of the fundamental diagram through the following relations:

$$
Q=V D
$$

Where, $\mathrm{Q}$ is the traffic flow, $\mathrm{D}$ is the traffic density and $\mathrm{V}$ is the velocity.

Through empirical studies of massive urban traffic flow data (Geroliminis and Daganzo 2008) and simulation results (Gartner and Wagner 2004), it was found that the speed-flow macroscopic fundamental diagram follows a parabolic-like pattern, which can be revealed by plotting the flow-speed diagram (see Figure 2(a)) and performing a regression (Bellomo et al. 2002):

$$
Q=a V^{2}+b V
$$

Where, $a$ and $b$ are the parabolic fitting parameters, which are estimated by regression.

(a)

Recent studies mainly focus on verification of the macroscopic fundamental diagram which takes the space-mean speed and density as inputs (Buisson and Ladier 2009; Daganzo et al. 2011). In this paper, it is assumed that the chosen road segment has such a parabolic pattern for the flow-speed relation, and for simplification the average speed and flow have been used. However, if the road segment to be analysed were larger, more complicated methods can be adopted.

For Step 4 we selected two segments of the assumed route on Parramatta Road (Sydney's main western arterial road) between Strathfield and the CBD $(10.3 \mathrm{~km})$. From the Sydney Coordinated Adaptive Traffic System (SCATS) we obtained vehicle flow rate and speed data for 15 minute intervals over the AM peak for those study segments and derived an elasticity of travel time with flow rate with a parabolic regression function (Step 5 - see Figure 2(a) and (b)).

Using these regression relations with the estimate of flow reduction along the same road segments due to the utilization of SWC, we achieve Step 6 of our process: an estimate of reduced travel time during the peak AM commute.

\section{RESULTS}

From the census, JTW and skim matrix data we were able to identify 8 candidate SA2 locations for SWC based on $>=50$ minute average commute time in private motorised vehicles, and total number of trips to Sydney CBD during the morning peak period (refer to Figure 1 and Table 1).

Taking the M4 Motorway and Parramatta Road as the predominant route to this same destination, there are a maximum possible number of 890 trips that could

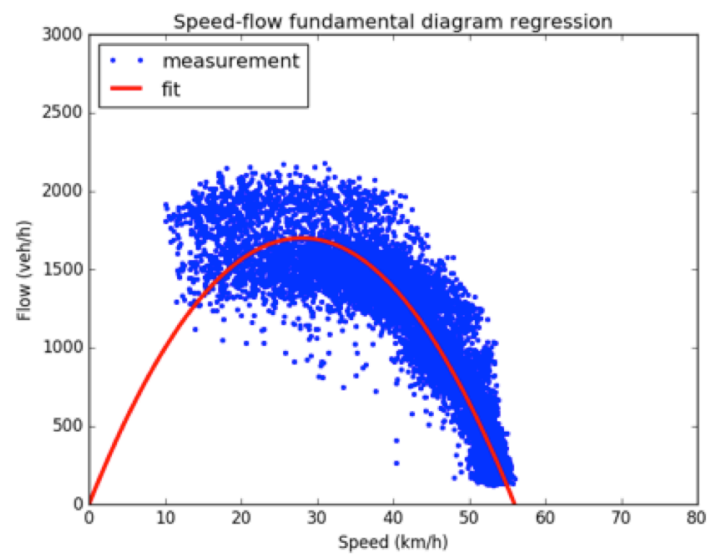

(b)

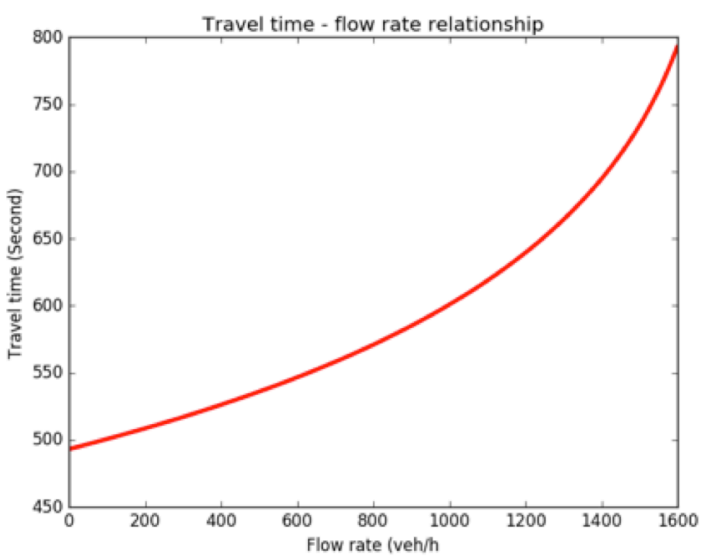

Figure 2. a) parabolic regression (red line) fitted to traffic flow (vehicles/hour) versus velocity based on

15 min interval data (blue dots) from SCATS b) derived parabolic function for a $10.3 \mathrm{~km}$ segment of Parramatta Road, Sydney be substituted for with the use of SWCs. With conservative assumptions about the uptake and utilization of SWC, we estimate that 206 trips would be substituted for on a given workday morning. Spreading this reduction over the 2.5 hour peak AM period results in a flow reduction of approximately 82 vehicles/hour. 
Baynes, Wen, Nguyen and Chen, Getting to work: smart work centers reduce morning peak traffic flow

We have developed an empirical relationship for travel time versus flow rate for the specific road segments of Parramatta Road between Strathfield and Sydney CBD.

Using this relationship and the flow reduction leads to the following statement: the collective reduction in vehicle flow due to the use of $8 \mathrm{SWC}$ is likely to effect a saving of approximately 1minute travel time for all commuters on the study road segments during the morning peak period. This is a conservative estimate and does not include the time saved by more than 200 individuals who use the SWCs and avoid a commute entirely (total $\sim 170$ hours/day). A greater number, or uptake, of SWC would likely result in further traveltime saving.

\section{DISCUSSION}

Whereas previous studies on SWC have investigated an assumed location of SWC or an assumed number of SWC in a metropolitan area, we have developed an empirical basis for SWC locations close to where workers, in relevant occupations, reside. Wilmot et al (2014) looked at the time savings to workers who use SWCs and we have further estimated the indirect apparent time savings to all commuters for a specific route choice. We have concentrated on a single route for West to East commuting in the Sydney GMA to provide a proof-of principle result. This shows that the analysis is worthwhile expanding to include multiple commuter origins, multiple work destinations and multiple route choices. Such a simulation would likely involve considerable computing resources.

Even within our relatively simple model, several improvements are possible. Data on relative flows by different routes to Sydney CBD would refine the assumption about route choice proprtions from origin SA2 locations. We have assumed that the flow reduction is spread uniformly across the peak AM period when it is possible the incidence of flow reduction might occur over a more concentrated interval. Distribution of the departure time of for trips from origins would help in this regard. The analysis could be performed at a higher spatial resolution: at the level of transport zones ( 3000 in Sydney GMA). However, there is no finer resolution on origin of occupations than SA2 boundaries. Any mapping to transport zones would effectively involve a downscaling estimation to disaggregate current census information and so there would be no real improvement in resolution.

The result of a 1minute time saving needs to be placed in perspective of the scale and cost of infrastructure to achieve similar outcomes. By 2031, the $\$ 16.8$ billion WestConnex project ${ }^{2}$ aims to deliver, among other outcomes, an approximate travel time saving of 10 minutes along the exact same route as our study (Sydney Motorway Corporation 2015). It may be readily appreciated that even 100 SWCs (ten times our study) would involve considerably less investment and may even present as an opportunity for direct private investment in property management. To provide a more rigorous comparison further research is required: investigating the effect of a larger population of SWC on the same study segment; assessing the effect of a larger population of SWC on the metropolitan road network and; surveying the latent demand commuting population regarding likely uptake. There is also the need to consider multiple destinations for work and other activities.

We have not measured the economic value of time-savings and reduced congestion although this would be a relatively simple extension as in Wilmot et al (2014). There are also possible indirect benefits to the local economy and community (as a location of new employment activity) coupled with personal benefits of timesavings for SWC users related to improving work-life balance: less time spent commuting means more time spent with family or volunteering or just enjoying a less stressful, healthier lifestyle. The latter features are actually an important part of the putative effectiveness of SWC. In many other system interventions there are feedbacks and 'rebound effects' whereby the initial action (reducing congestion) leads to a perverse outcome (greater uptake of private transport) exacerbating the original problem. When the effect of the intervention is in multiple dimensions, (e.g. reduced congestion AND personal convenience and lifestyle), there is the potential to ameliorate the rebound effect because the value of diverse benefits cements behavior and preferences into a new regime. For example, implementing SWC at scale may reduce travel-times but if SWC users value the lifestyle change highly, they may not return to commuting even though it becomes less costly. Again, further research through surveying SWC users and their choices would refine this hypothesis.

SWC are an aspect of land use and therefore can be part of urban planning. At the same time they clearly have a quantitative connection with the transport system and relate to industry and productivity. As such, they present a bridge between policy areas, enabling and perhaps requiring more coordination across government.

\footnotetext{
2 https://www.westconnex.com.au/
} 
Baynes, Wen, Nguyen and Chen, Getting to work: smart work centers reduce morning peak traffic flow

\section{CONCLUSION}

Using census and JTW data we have identified locations for SWCs in the Sydney GMA. Conservative utilization of 8 SWCs results in reduced traffic flow and, with a transport model, we estimate a generalised peak AM travel-time saving of 1 minute over a $10.3 \mathrm{~km}$ segment of the main west-east arterial road. This proof-of-principle result is achieved with only $200 \mathrm{SWC}$ users and suggests that SWCs implemented at scale $(>>10$ SWCs) could further reduce congestion and respond to calls for better use of existing infrastructure, better connectivity and access to employment opportunities in outer suburbs. There are potentially substantial social gains from such a scenario in Australian cities but further modeling and survey research is required.

\section{ACKNOWLEDGEMENTS}

This research has been funded by the Land and Water Division of CSIRO.

\section{REFERENCES}

ABS (2011a) ABS Catalogue 1270.0.55.001 - Australian Statistical Geography Standard (ASGS): Volume 1 - Main Structure and Greater Capital City Statistical Areas. Australian Bureau of Statistics Australia. Available http://www.abs.gov.au/AUSSTATS/abs@.nsf/Lookup/1270.0.55.001Main+Features1July+2011.

ABS (2011b) Australian Census Data - Basic Community Profile Table 34 Canberra, Australia. Available at http://www.abs.gov.au/websitedbs/censushome.nsf/home/historicaldata.

ABS (2013) Population Projections, Australia, 2012 (base) to 2101 ABS 32220. Australian Bureau of Statistics, Canberra. Available at http:/www.abs.gov.au/Ausstats/abs@.nsf/mf/3222.0.

Bell, MG, Iida, Y (1997) Transportation network analysis.

Bellomo, N, Delitala, M, Coscia, V (2002) On the mathematical theory of vehicular traffic flow I: Fluid dynamic and kinetic modelling. Mathematical Models and Methods in Applied Sciences 12, 18011843.

BITRE (2015) 'Traffic and congestion cost trends for Australian capital cities - Information sheet $74 . '$ (Bureau of Infrastructure, Transport and Regional Economics: Canberra, Australia)

BTS (2011a) BTS Skim Matrices obtained through personal communication with Malcolm Bradley at the former NSW Bureau of Transport Statistics (now Transport Performance and Analytics). (NSW Bureau of Transport Statistics [Accessed May 2016].

BTS (2011b) Journey to Work (JTW) 2011 (NSW Bureau of Transport Statistics Available at https://opendata.transport.nsw.gov.au/dataset/journey-work-jtw-2011 [Accessed August 2017].

Buisson, C, Ladier, C (2009) Exploring the impact of homogeneity of traffic measurements on the existence of macroscopic fundamental diagrams. Transportation Research Record: Journal of the Transportation Research Board 127-136.

Buksch, B, Davidson, J (2014) Digital Work Hubs: An Activation Framework for South East Queensland. Regional Development Australia Available at digitalworkhub.com.au.

Daganzo, CF, Gayah, VV, Gonzales, EJ (2011) Macroscopic relations of urban traffic variables: Bifurcations, multivaluedness and instability. Transportation Research Part B: Methodological 45, 278-288.

Gartner, N, Wagner, P (2004) Analysis of traffic flow characteristics on signalized arterials. Transportation Research Record: Journal of the Transportation Research Board 94-100.

Geroliminis, N, Daganzo, CF (2008) Existence of urban-scale macroscopic fundamental diagrams: Some experimental findings. Transportation Research Part B: Methodological 42, 759-770.

Infrastructure Australia (2016) 'Australian Infrastructure Plan: Priorities and reforms for our nation's future.' (Infrastructure Australia:

INRE (2013) Overview on the Smart Work Centres in Europe. Institute of National and Regional Economy, Riga Technical University, Riga, Latvia. Available at http://www.micropol-interreg.eu/.

Sydney Motorway Corporation (2015) Technical Paper 1 - Traffic report. Available at https://http://www.westconnex.com.au/sites/default/files/Tech Paper 1 - Traffic report Final.pdf.

Veitch Lister Consulting Pty Ltd (2014) Greater Sydney - Travel modelling report. prepared for Infrastructure Australia Available at http://infrastructureaustralia.gov.au/policypublications/publications/files/Traffic-modelling-report-Sydney.pdf.

Wilmot, K, Boyle, T, Rickwood, P, Sharpe, S (2014) Smart Work Centres: An Analysis of Demand in Western Sydney. Institute for Sustainable Futures, University of Technology Sydney, Sydney. 